Board of Governors of the Federal Reserve System

International Finance Discussion Papers

Number 510

June 1995

\title{
OPTIONS, SUNSPOTS, AND THE CREATION OF UNCERTAINTY
}

David Bowman and Jon Faust

Note: International Finance Discussion Papers are preliminary materials circulated to stimulate discussion and critical comment. References in publications to International Finance Discussion Papers (other than an acknowledgement that the author has had access to unpublished material) should be cleared with the author or authors. 


\begin{abstract}
$\underline{\text { Abstract }}$
We present a model in which the addition of an option market leads to sunspot equilibria in an economy which has no sunspot equilibrium before the market is int:oduced. This phenomenon occurs because the payoff of an option contract is contingent upon market prices, and while prices are taken as exogenous by individuals within the economy they are endogenous to the economy as a whole. Our results provide robust counterexamples to the two most prevalent views of options markets in finance. Following Ross [1976], it is often assumed that the addition of option contracts to an incomplete markets economy can help complete markets. We demonstrate that the addition of option markets can instead increase the number of events which agents need to insure against. Following Black-Scholes [1973], it is often assumed that the economy is such that options are redundant. We demonstrate equilibria in which an added option market is not redundant even when markets were complete before its introduction.
\end{abstract}




\title{
Options, Sunspots, and the Creation of Uncertainty
}

\author{
David Bowman and Jon Faust ${ }^{1}$
}

The past twenty years have witnessed an impressive expansion in the number and type of financial derivatives available to investors. There are two common views of these markets within finance. First, many of them are viewed as redundant. In particular, there is a large body of work on pricing options when the returns they generate can be duplicated using existing assets (e.g. Black and Scholes [1973]). Second, financial innovation is explained as the natural outcome of an incomplete se; of existing financial markets - each new financial instrument is conjectured to allow for insurance against a larger set of states of nature than could be insured against before its introduction. Ross [1976] demonstrated the potential role for options in this process by proving that when prices of existing assets differ across states, the introduction of the right set of option contracts on existing assets can complete the market in the same way that adding Arrow securities would in an incomplete financial markets extension of Arrow [1953].

Options differ, however, in a fundamental way from the assets originally envisioned by Arrow. While the payoffs of Arrow's assets were explicitly contingent upon the realized state of nature (state contingent), the payoffs of options are contingent upon the price of some underlying security (price contingent). State contingent securities provide insurance contracts against events which are exogenous; price contingent securities are insurance contracts against price movements, which

\footnotetext{
1 The authors are staff economists in the Division of International Finance, Board of Governors of the Federal Reserve System. This paper represents the views of the authors and should not be interpreted as reflecting the views of the Board of Governors of the Federal Reserve System or other members of its staff. We thank Alex David, Greg Duffee, Mark Fisher, and Christian Gilles for helpful comments. Mailing Address: Stop 24, Division of International Finance, Board of Governors of the Federal Reserve System, Washington, D.C. 20551. Email: bowmand@frb.gov or faustj@frb.gov
} 
may be taken as exogenous by individual agents, but are endogenous to the economy. We demonstrate that the price contingent nature of options can create robust counterexamples to both of the prevalent views of option markets: the addition of option contracts to a complete markets economy can endogenously increase the set of events against which agents wish to insure, leaving markets incomplete.

We present two examples within the context of a simple three-period production economy. The first involves two intrinsic states of nature and a single asset, so that markets are incomplete. ${ }^{2}$ As in Ross [1976], adding an option can complete markets and lead to a Pareto optimal equilibrium. However we also demonstrate a second outcome in which a sunspot equilibrium is created, so that there are three states and the two assets do not provide a complete set of markets.

The second example begins with two intrinsic states and two assets, a stock and a bond, which give rise to a unique, Pareto optimal equilibrium allocation. This economy conforms to the environment studied in Cox, Ross, and Rubinstein's [1979] discrete-time version of the Black-Scholes option pricing model. In this case adding an option on the stock leads to one equilibrium in which the option is redunclant as in Black-Scholes. However there is also a second sunspot equilibrium in which there are four states and the three assets do not provide a complete set of markets. Despite the existence of a complete set of markets before the option was added the option is not, and cannot be priced as if, redundant in the sunspot equilibrium. Thus, even the fact that existing asset markets are complete and support a unique equilibrium is not sufficient to guarantee that a new option market will be redundant. The common practice of pricing newly introduced option contracts as if they vere redundant must rest on stronger assumptions.

The intuition behind these results is straightforward. A movement in the price of an asset on which an option has been written would not change the return of a statecontingent security, but it will change the return of the option contract and thereby

\footnotetext{
${ }^{2}$ In the terminology of Shell [1977] and Cass and Shell [1983], an intrinsic state of nature is any state which distinguishes agent's endowments or preferences. An extrinsic state of nature is the realization of some random variable which affects neither endowments or preferences (e.15., a sunspot).
} 
reallocate wealth across investors. This wealth reallocation will, in general, change excess demand and can help support the price change as a new equilibrium. For this reason the introduction of option markets can create equilibria in which uncertainty about endogenous market events (e.g., sunspots) is supported - the payoff of an option contract depends only on price movements, and does not distinguish whether these price movements are caused by market fundamentals or non-fundamentals. If individuals take prices as given, then they will treat price movements as exogenous in the same way that states of nature are taken as exogenous, and so will be unable to realize that the effects of introducing price contingent assets may differ from the effects of introducing state contingent assets. This argument has a family resemblance to arguments made about the contribution of price contingent trading to the October 1987 stock market crash-an initial move in stock prices triggered price contingent trades, reallocating wealth and leading to a new equilibrium (see, e.g., Gennotte and Leland [1990]).

Our results can be usefully contrasted with other work studying economies with option markets. Polemarchakis and $\mathrm{Ku}$ [1990] construct a robust example of nonexistence of an equilibrium in an exchange economy with options which relies on a discontinuity in excess demand generated by the option contract. ${ }^{3}$ Our examples stem simply from the price contingency of options and do not rely on any discontinuity in excess demand. Extending an argument in Mas-Collel [1992], Kajii [1991] demonstrated that a continuum of options contracts on any single underlying asset will generically rule out any sunspot equilibrium with a finite set of states. Our point is the opposite: even when there is a unique, no-sunspot equilibrium of the underlying economy, the addition of option markets can generate sunspot equilibria.

It is well-known that sunspot equilibria may be generated when there are multiple equilibria of the underlying economy, and that in incomplete markets models with nominal assets there may be a large degree of indeterminacy (see Cass $[1989,1992]$ and references therein, Balasko and Cass [1989], Geanakoplos and Mas-

\footnotetext{
${ }^{3}$ Krasa [1989] derives sufficient conditions for existence in such a setting.
} 
Collel [1989], and Krasa and Werner [1991]). In our examples agents trade only real assets. We highlight the role of price contingency by demonstrating that options can give rise to endogenous uncertainty even when the underlying economies-absent price contingent assets-have unique equilibria for any distribution of endowments. This answers a question posed by Mas-Collel [1992] as to whether sunspot equilibria were possible in such a context. Hens [1994] provides an example in which agents trade assets which are explicitly contingent upon the realization of a sunspot variable which also has this feature. ${ }^{4}$

In Section 1, we present the three-period economy from which our resultsi are derived. Section 2 presents an example in which financial markets are initially incomplete and the addition of an option market can either complete the market or create sunspot equilibria. Section 3 presents an example in which markets are initially complete and the addition of an option market leads to a sunspot equilib:cium in which markets are incomplete. Section 4 discusses the robustness of these results and concludes.

\section{The Economy}

We consider a three-period economy with two agents, one firm, and two intrinsic states of nature. In each of the first two periods agents receive an endowment of a single consumption good and trade both the good and a set of financial assets. In the initial period the firm decides how much of the consumption good to purchase and invest in a production technology which will pay off in the last period. The firm distributes the proceeds of this investment as a final period dividend. Both the agents and the firm take prices as given; agents maximize expected utility; the firm maximizes its market value.

We label the two individuals, $h=i, j$, and the three periods, $t=0,1,2$. Agent $h$ receives positive endowment $w_{h t}$ at time $t=0,1$; there are no endowments at time

\footnotetext{
'Hen's conclusion is cited in Mas-Collel [1992].
} 
2. Defining $c_{h t}$ as $h$ 's consumption at time $t, h$ 's preferences are given by:

$$
u_{h}=E_{0} \sum_{t=0}^{2}\left(\beta_{h}\right)^{t} \ln \left(c_{h t}\right)
$$

For simplicity, the sole source of intrinsic uncertainty regards the realization of agents' preferences at time 1 . We assume that it is common knowledge that with equal probability either $\left(\beta_{i}, \beta_{j}\right)=\left(\bar{\beta}_{i}, 0\right)$ or $\left(\beta_{i}, \beta_{j}\right)=\left(0, \bar{\beta}_{j}\right)$ at time 1 , where $\bar{\beta}_{i}$ and $\bar{\beta}_{j}$ are strictly positive. ${ }^{5}$ Under this assumption, when time 1 arrives only one of the two agents will desire consumption. This allows for closed form solutions and simple intuitions regarding equilibria, however it is not central to the results. As discussed in Section 4, we have numerical solutions with similar results in examples which do not make this assumption.

The firm has an irreversible linear production technology which transforms one unit of the consumption good at time 0 into $A$ units at time 2. At time 0 the initial shareholders of the firm decide upon an amount to be invested. This amount is rajsed from initial shareholders in the form of a negative dividend at time 0 , and the proceeds are paid out as a dividend at time 2 . No dividend is paid at time 1. The dividend at $t$ is $d_{t}$.

In addition to uncertainty concerning the realization of preferences at time 1 , we allow for the existence of extrinsic uncertainty concerning market prices. Define a state at time $t$ to be a realization through time $t$ of all variables taken as exogenous by agents. For convenience, we collapse any extrinsic states of nature in which prices are identical into a single event, so that each state, $s_{t}$, is assumed to represent a unique realization of preferences, endowments, and asset prices up to and including tirne $t .^{6}$ There is a single state at time $0, s_{0}$. Let $S_{t}$ be the full set of states which may occur at time $t$, and $S$ be the set $\left\{S_{t}\right\}, t=0,1,2$. The probability with which each state occurs - the joint distribution of elements of $S$-is public information.

\footnotetext{
${ }^{5}$ When $\beta_{h}=0$ and agent $h$ has positive income at time 1 , we take $h$ 's time 1 and 2 demands (conditional on time 1 income) to be the limit of these demands as $\beta_{h} \rightarrow 0$.

${ }^{6}$ We thus ignore trivial sunspot equilibria, in which extrinsic uncertainty exists but has no effect on equilibrium allocations - by our definition the set of states consists only of events which have sorne effect on the economy.
} 
For each $s_{t}$, let $\pi\left(s_{t}\right)$ be the unconditional probability that state $s_{t}$ occurs. Define $c_{h}\left(s_{t}\right)$ as $h$ 's consumption at time $t$ in state $s_{t}$, and define $\beta_{h}\left(s_{t}\right) \in\left\{0, \bar{\beta}_{h}\right\}$ ais $h$ 's discount factor at time $t$ in state $s_{t}, t=1,2 .^{7}$

At each time agents may trade a set of $N$ assets. The $N \times 1$ vector of gross one-period returns in terms of the consumption from holding assets to time $t$, state $s_{t}$, is $x\left(s_{t}\right)=\left(\ldots, x_{n}\left(s_{t}\right), \ldots\right)$. Similarly, the vector of ex dividend asset prices in terms of the consumption good is $p\left(s_{t}\right)=\left(\ldots, p_{n}\left(s_{t}\right), \ldots\right)$. Agent $h$ 's end-of-period asset holdings in $s_{t}$ are $y_{h}\left(s_{t}\right)=\left(\ldots, y_{h n}\left(s_{t}\right), \ldots\right)$. Initial time 0 holdings are $y_{h}\left(3_{-1}\right)$.

Each individual's problem is to choose $\left(c_{h}, y_{h}\right) \equiv\left\{c_{h}\left(s_{t}\right), y_{h}\left(s_{t}\right) ; t=0,1,2, s_{t} \in\right.$ $\left.S_{t}\right\}$ to maximize $u_{h}$ subject to:

$$
\begin{aligned}
& c_{h}\left(s_{t}\right)=w_{h t}+y_{h}\left(s_{t-1}\right) \cdot x\left(s_{t}\right)-y_{h}\left(s_{t}\right) \cdot p\left(s_{t}\right) \\
& c_{h}\left(s_{t}\right) \geq 0 .
\end{aligned}
$$

Let $p_{1}\left(s_{0}\right)$ be the price of a sure claim to one unit of consumption at time 2 . The firm's problem is to choose $d_{0}$ to maximize ${ }^{8}$

$$
d_{0}+p_{1}\left(s_{0}\right) d_{2}
$$

subject to

$$
d_{2}=-A d_{0}, \quad d_{0} \leq 0
$$

It is convenient to think of agents as directly trading equity contracts, rather than claims to consumption at time 2. If we define $p_{e}\left(s_{t}\right)$ and $x_{e}\left(s_{t}\right)$ as the price and return of equity in the firm, then $p_{e}\left(s_{t}\right) \equiv p_{1}\left(s_{t}\right) d_{2}$ and $x_{e}\left(s_{t}\right) \equiv x_{1}\left(s_{t}\right) d_{2}$.

Following Radner [1972], given a set of states $S$ and probabilities $\pi$, an equilibrium is an allocation $\left\{\left(c_{i}, y_{i}\right),\left(c_{j}, y_{j}\right), d_{0}\right\}$ such that given prices and asset returns, $\left(c_{h}, y_{h}\right)$ maximizes $u_{h}$ subject to (1) and (2), $h=i, j ; d_{0}$ maximizes the market value

\footnotetext{
${ }^{7}$ We impose the rational expectations constraint that the joint distribution of preferences inder $\pi$ and $S$ is consistent with the true exogenous distribution.

${ }^{8}$ In parts of what follows there may be an incomplete set of financial markets, but becausie the firm's technology is linear it satisfies a spanning condition which implies that at any equilibrium initial shareholders will unanimously agree upon maximization of the market value of the firm regardless of market completeness (see Ekern and Wilson [1974] and Radner [1974]).
} 
of the firm subject to (3); and

$$
\begin{aligned}
c_{i}\left(s_{t}\right)+c_{j}\left(s_{t}\right) & =w_{i t}+w_{j t}+d_{t} \\
y_{i}\left(s_{t}\right)+y_{j}\left(s_{t}\right) & =\bar{y} .
\end{aligned}
$$

where $\bar{y}=\left(\ldots, \bar{y}_{n}, \ldots\right)$ and $\bar{y}_{n}$ is the net supply of asset $n$. The net supply of equity is normalized to one, and all other assets are in zero net supply.

A sunspot equilibrium is defined as an equilibrium in which at time $t=1$ or 2 there exist at least two states in which preferences are the same, but prices are different. That is, there exist $s_{t}, s_{t}^{\prime} \in S_{t}$ such that $\beta_{h}\left(s_{t}\right)=\beta_{h}\left(s_{t}^{\prime}\right), h=i, j$, and $p\left(3_{t}\right) \neq p\left(s_{t}^{\prime}\right)$.

A Pareto optimal allocation at time 0 must satisfy $c_{i 0}=\frac{\lambda}{1-\lambda} c_{j 0}=\eta\left(w_{i 0}+w_{j 0}\right)$, where $\lambda \in(0,1)$ and $\eta=\frac{2(1-\lambda)}{2+\lambda \bar{\beta}_{i}^{2}+(1-\lambda) \bar{\beta}_{j}^{2}}$. The Pareto optimal allocation at time 1 and 2 is obvious - all available resources will be consumed by the agent with the positive discount factor:

$$
c_{h}\left(s_{t}\right)=\left\{\begin{array}{cc}
0 & \text { if } \beta_{h}\left(s_{t}\right)=0 \\
w_{i t}+w_{j t}+d_{t} & \text { if } \beta_{h}\left(s_{t}\right) \neq 0
\end{array} .\right.
$$

Given logarithmic utility, preferences satisfy the gross substitutes property, which is sufficient for a unique, Pareto optimal equilibrium of the economy with a complete set of Arrow-Debreu state contingent claims.

\section{Adding an option to complete the market}

In this Section we begin with an economy in which the only asset is equity in the firm. An equilibrium of this "stock market economy" is free of sunspots, but agents cannot fully insure against the two possible intrinsic states with one asset, implying that the equilibrium is not Pareto optimal. Following Ross [1976], the addition of an option on the firm's equity can support a Pareto optimal allocation of the economy. There are, however, also sunspot equilibria of this "stock-option economy."

When equity is the only asset, $x\left(s_{t}\right)$ and $p\left(s_{t}\right)$ are scalars, and the gross return to holding the equity is $x\left(s_{t}\right)=p\left(s_{t}\right)+d_{t}$. We immediately have the following: 
Claim 1 (i) There are no sunspot equilibria of the stock market economy. (ii) No equilibrium of the stock market economy is Pareto optimal.

Proof: (i) At at time 2 there is no further demand for financial contracts, therefore $p\left(s_{2}\right)=0$ for all $s_{2} \in S_{2}$ in equilibrium. Thus, all uncertainty is resolved at time 1. In this case it is sufficient to show that there is a unique equilibrium equity price for each realization of preferences at time 1. Taking $y_{h}\left(s_{0}\right)$ as given, $h$ 's demand for time 1 consumption in state $s_{1}$ is:

$$
c_{h}\left(s_{1}\right)=\delta_{h}\left(s_{1}\right)\left(w_{h 1}+y_{h}\left(s_{0}\right) \cdot x\left(s_{1}\right)\right)
$$

where $\delta_{h}\left(s_{1}\right)=\frac{1}{1+\beta_{h}\left(s_{1}\right)}$. In equilibrium, (7) holds for both agents and the resource constraint (4) holds at time 1 . The implies the unique solution:

$$
p\left(s_{1}\right)=\frac{\beta_{i}\left(s_{1}\right) \delta_{i}\left(s_{1}\right) w_{i 1}+\beta_{j}\left(s_{1}\right) \delta_{j}\left(s_{1}\right) w_{j 1}}{\delta_{i}\left(s_{1}\right) y_{i}\left(s_{0}\right)+\delta_{j}\left(s_{1}\right) y_{j}\left(s_{0}\right)}
$$

Since the right hand side of this equation depends only upon the realization of preferences, $p\left(s_{1}\right)$ cannot depend on the realization of any sunspot variable.

(ii) Using (6) and (7), an equilibrium allocation of the stock market economy can be Pareto optimal only if $w_{h 1}+y_{h}\left(s_{0}\right) \cdot p\left(s_{1}\right)=0$ whenever $\beta_{h}\left(s_{1}\right)=0$. However since equilibrium prices must be strictly positive, $y_{h}\left(s_{0}\right)=-\frac{w_{h 1}}{p\left(s_{1}\right)}$ would imply that both $y_{i}\left(s_{0}\right) \leq 0$ and $y_{j}\left(s_{0}\right) \leq 0$, which violates the equilibrium condition $y_{i}\left(s_{0}\right)+y_{j}\left(s_{0}\right)=1$

The suboptimality of the stock market equilibrium provides an incentive to introduce a further set of assets in order to complete the market. Ross [1976] provides conditions under which, in a partial equilibrium setting, adding a set of call and put options on a portfolio of existing assets can bring about a equilibrium in vrhich markets are complete. ${ }^{9}$ McManus [1986] has extended Ross' argument in a general

\footnotetext{
${ }^{9}$ See also Friesen [1979], Green and Jarrow [1987], and Brown and Ross [1991]. Ross assumed that the returns on existing assets would not change when options contracts were introduced. In general equilibrium this is generically not the case (Detemple and Selden [1991]).
} 
equilibrium setting by demonstrating that prices in Arrow-Debreu equilibria generically differ across states, so that a set of options contracts can be chosen which support an equilibrium with complete markets. In the present case consider the economy resulting from the addition of a one-period European call option on equity with strike price $k$. Now $x_{n}, p_{n}$, and $y_{n}^{h}, n=e, o$, are the gross return, price, and $h$ 's end-of-period holdings of the equity $(n=e)$ and option $(n=o)$ respectively, where $x_{o}\left(s_{t}\right)=\max \left[p_{e}\left(s_{t}\right)-k, 0\right]$.

Claim 2 There is an equilibrium of the stock-option economy which supports a Pcireto optimal allocation if and only if $\bar{\beta}_{i} \neq \bar{\beta}_{j}$ and

$$
k<\min \left[\bar{\beta}_{i}\left(w_{i 1}+w_{j 1}\right), \bar{\beta}_{j}\left(w_{i 1}+w_{j 1}\right)\right]
$$

Proof: To prove sufficiency assume that there are two states at time $1, s_{i}$ and $s_{j}$, where $\bar{\beta}_{i}>0$ in $s_{i}$ and $\bar{\beta}_{j}>0$ in $s_{j}$. Equations (6) and (7) imply that $p_{e}\left(s_{i}\right)=$ $\bar{\beta}_{i}\left(w_{i 1}+w_{j 1}\right)$ and $p_{e}\left(s_{j}\right)=\bar{\beta}_{j}\left(w_{i 1}+w_{j 1}\right)$ at a Pareto optimal allocation. If $p_{e}\left(s_{i}\right) \neq$ $\left.p_{e}^{\prime}, s_{j}\right)$ and $k<\min \left[p_{e}\left(s_{i}\right), p_{e}\left(s_{j}\right)\right]$ then the stock and option allow for a complete sel; of markets and support a Pareto optimal allocation. To prove necessity, note that if $p_{e}\left(s_{i}\right)=p_{e}\left(s_{j}\right)$ or $k \geq \min \left[p_{e}\left(s_{i}\right), p_{e}\left(s_{j}\right)\right]$, then the option is redundant and the equilibrium allocation must correspond to an equilibrium allocation of the stock market economy.

The top panel of Table 1 provides an example of a stock market equilibrium and the bottom panel presents the unique Pareto optimal stock-option equilibrium. Eecch equilibrium has two states, one associated with each realization of preferences.

While the addition of the option contract to the stock market economy can support a Pareto optimal allocation, it does not necessarily do so. In fact, as we next demonstrate, it can instead increase the number of events agents wish to insure against:

Claim 3 There are sunspot equilibria of the stock-option economy. 


\begin{tabular}{|c|c|c|c|c|c|}
\hline$t, s_{t}$ & $p_{e}\left(s_{t}\right)$ & $p_{o}\left(s_{t}\right)$ & $c_{i}\left(s_{t}\right)$ & $c_{j}\left(s_{t}\right)$ & $d_{0}$ \\
\hline \multicolumn{6}{|c|}{ stock market economy } \\
\hline $0, s_{0}$ & 0.38 & & 0.94 & 1.18 & -0.38 \\
\hline $1, s_{i}$ & 1.60 & & 1.78 & 0.22 & \\
\hline $1, s_{j}$ & 0.36 & & 1.54 & 0.46 & \\
\hline \multicolumn{6}{|c|}{ stock-option economy } \\
\hline $0, s_{0}$ & 0.67 & 0.28 & 1.02 & 0.81 & -0.67 \\
\hline $1, s_{i}$ & 1.8 & & 2 & 0 & \\
\hline $1, s_{j}$ & 1.6 & & 0 & 2 & \\
\hline
\end{tabular}

Parameters: $\beta_{i}>0$ in state $s_{i}, \beta_{j}>0$ in state $s_{j}$. $\left(\bar{\beta}_{1}, w_{i 0}, w_{i 1}\right)=\left(\frac{9}{10}, \frac{3}{2}, 1\right),\left(\bar{\beta}_{j}, w_{j 0}, w_{11}\right)=\left(\frac{8}{10}, 1,1\right)$ $A=k=1 . \pi\left(s_{i}\right)=\pi\left(s_{\jmath}\right)=\frac{1}{2}$.

Table 1: Using an option to complete the market.

Proof: See the Appendix.

The intuition of this result can be seen in a partial equilibrium setting beginning from the Pareto optimal equilibrium in the bottom panel of Table 1. Focus exclusively on time 1 state $s_{i}$. We demonstrate that there may be two equilibr:ium outcomes for this intrinsic state when agents hold option contracts. This makes three possible outcomes for the economy seen at time 0 , and implies that the two financial assets cannot provide a complete set of markets. In the bottom panel of Table 1 , the option is executed in state $s_{i}$. Suppose instead that agents did not execute the option. To compute the time 1 equity price in this case, form an expression for the time 1 equity price conditional on the asset holdings at the end of time 0 and the stipulated execution or non-execution of the option. The generalization of (8) is

$$
p_{e}\left(s_{1}\right)=\frac{\beta_{i}\left(s_{1}\right) \delta_{i}\left(s_{1}\right)\left(w_{i 1}+\chi y_{i o}\left(s_{0}\right) k\right)+\beta_{j}\left(s_{1}\right) \delta_{j}\left(s_{1}\right)\left(w_{j 1}+\chi y_{j o}\left(s_{0}\right) k\right)}{\delta_{i}\left(s_{1}\right)\left(y_{i e}\left(s_{0}\right)+\chi y_{i o}\left(s_{0}\right)\right)+\delta_{j}\left(s_{1}\right)\left(y_{j e}\left(s_{0}\right)+\chi y_{j o}\left(s_{0}\right)\right)}
$$

where $\chi$ is 1 if the option is executed, and 0 otherwise. If $\chi=1$, the equity price from the bottom panel of Table 1 obtains, $p_{e}\left(s_{i}\right)>k$, and execution of the option is rational. However, if $\chi=0$ and $p_{e}\left(s_{1}\right)<k$ then presumed non-execution is 


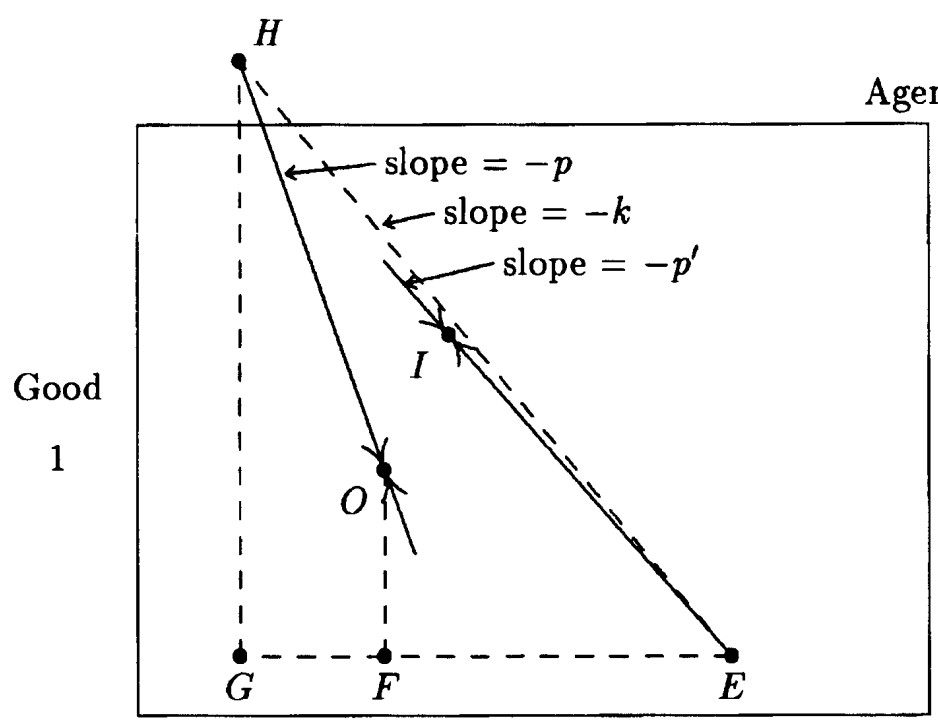

Agent $i$

Good 2

Figure 1: Time 1, state $s_{i}$

rational as well. This raises the possibility of an equilibrium in which at time 1 the equity price may be either greater or smaller than the option strike price depending upon the realization of some extrinsic random variable. Of course, this discussion has been conditional on time 0 decisions. The proof of Claim 3 makes clear that sunspot equilibria are possible when agents' time 0 decisions take account of the pcissibility of two outcomes in state $s_{i}$.

A graphical representation of the partial equilibrium argument may be useful. St.ppose that time 1 state $s_{i}$ is represented by the Edgeworth box in Figure 1. The endowment point is $E$, and we stipulate that equilibrium consumption would be at point $O$ if there were state contingent markets for both goods and all states at time 0 (associate $O$ with the allocation in at time 1 in state $s_{i}$ in the bottom panel of Table 1). Clearly, point $O$ could be achieved if agent $i$ came to time 1 with a claim to good 1 in state $s_{i}$ in the amount represented by the length of segment $O F$, and $j$ arrived with a claim to an amount $E F$ of good 2. The implied equilibrium spot market relative price of good 2 in terms of $\operatorname{good} 1$ is $p$. Point $O$ is the unique equilibrium if the agents arrive at state $s_{i}$ with these assets. 


\begin{tabular}{cccccc}
\hline \hline$t, s_{t}$ & $p_{e}\left(s_{t}\right)$ & $p_{o}\left(s_{t}\right)$ & $c_{i}\left(s_{t}\right)$ & $c_{j}\left(s_{t}\right)$ & $d_{0}$ \\
\hline $0, s_{0}$ & 0.42 & 0.04 & 1.03 & 1.05 & -0.42 \\
$1, s_{i}$ & 1.8 & & 2 & 0 & \\
$1, \tilde{s}_{i}$ & 0.90 & & 1.00 & 1.00 & \\
$1, s_{j}$ & 0.44 & & 1.45 & 0.55 & \\
\hline \hline
\end{tabular}

Parameters: $\beta_{i}>0$ in states $s_{i}$ and $\tilde{s}_{i} ; \beta_{j}>0$ in state $s_{j} . \pi\left(s_{i}\right)=\pi\left(\tilde{s}_{i}\right)=\frac{1}{4} ; \pi\left(s_{3}\right)=\frac{1}{2}$. All other parameters identical to Table 1 .

Table 2: A sunspot equilibrium of the stock-option economy.

Point $O$ can also be attained using option contracts. For example, suppose that at time 0 there were a call option on good 2 with terminal date 1 and strike price $k$. Point $O$ could be attained if agent $j$ arrives at state $s_{i}$ holding call options for $E G$ units of good 2. The state obtains, and the relative price $p$ is called in the spot market by the Walrasian auctioneer. Since $p>k, j$ executes the option, moving the agents' holdings to point $H$. From that point, spot market trades at the frice $p$ take the agents' to $O$, supporting $p$ as an equilibrium price. Another outcome is possible, however. If the auctioneer calls out $p^{\prime}<k$, the option will not be executed, and $p^{\prime}$ is supported as an equilibrium with the allocation at point $I$.

Table 2 presents a sunspot equilibrium of the stock-option economy. In this equilibrium there are three states $s_{i}, \tilde{s}_{i}$, and $s_{j}$, where $i$ desires consumption in states $s_{i}$ and $\tilde{s}_{i}$, and $j$ desires consumption in state $s_{j}$. We have thus split the intrinsic state in which $i$ desires consumption into two states from the standpoint of the agents. The sunspot has important welfare effects: the equilibrium shown in Table 2 is Pareto inferior to both the stock market equilibrium and the stock-option equilibrium shown in Table 1.

\section{Adding an option to an already complete set of markets}

We now consider the same economy when agents can trade equity and a one-period risk-free bond. These two assets will generically provide a complete set of markets 
so that this "stock-bond economy" has a unique, Pareto optimal equilibrium. Let $x_{b}, p_{b}$, and $y_{b}^{h}$ be the gross return, price, and $h$ 's end-of-period holdings of the bond, where $x_{b}\left(s_{t}\right)=1$.

Claim 4 (i) There are no sunspot equilibria of the stock-bond economy. (ii) There is an equilibrium of the stock-bond economy which supports a Pareto optimal allocation if and only if $\bar{\beta}_{i} \neq \bar{\beta}_{j}$. (iii) If in addition

$$
\frac{\left(2+\left(\bar{\beta}_{j}\right)^{2}\right)\left(\bar{\beta}_{i}\right)^{2} w_{i 0}-2\left(\bar{\beta}_{j}\right)^{2} w_{j 0}}{\bar{\beta}_{i} \bar{\beta}_{j}\left(w_{i 0}+w_{j 0}\right)} \neq \frac{\left(1+\bar{\beta}_{i}\right) \bar{\beta}_{j} w_{j 1}-\bar{\beta}_{i} w_{i 1}}{\left(w_{i 1}+w_{j 1}\right)}
$$

then this equilibrium is unique.

Proof: (i) The proof that no sunspot equilibria exist is identical to the proof of part ( $i$ ) of Claim 2, except that (8) is changed to

$$
p\left(s_{1}\right)=\frac{\beta_{i}\left(s_{1}\right) \delta_{i}\left(s_{1}\right)\left(w_{i 1}+y_{i 1}\left(s_{0}\right)\right)+\beta_{j}\left(s_{1}\right) \delta_{j}\left(s_{1}\right)\left(w_{j 1}+y_{j 1}\left(s_{0}\right)\right)}{\delta_{i}\left(s_{1}\right) y_{i 0}\left(s_{0}\right)+\delta_{j}\left(s_{1}\right) y_{j 0}\left(s_{0}\right)}\left[\begin{array}{c}
1 \\
d_{2}
\end{array}\right] .
$$

(ii) By $(i)$, any equilibrium has two states at time 1 , which we label $s_{i}$ and $s_{j}$, where $\bar{\beta}_{i}>0$ in $s_{i}$ and $\bar{\beta}_{j}>0$ in $s_{j}$. The proof that there is an equilibrium of the stockbond economy which supports a Pareto optimal allocation when $\bar{\beta}_{i} \neq \bar{\beta}_{j}$ is identical to the proof of Claim 2. The assertion that there is only one such equilibrium follows from the fact that preferences satisfy the gross substitutes property. (iii) Since (ii) implies that there is a unique equilibrium in which $p_{e}\left(s_{i}\right) \neq p_{e}\left(s_{j}\right)$, we must only consider the possibility of equilibria in which $p_{e}\left(s_{i}\right)=p_{e}\left(s_{j}\right)$. If $p_{e}\left(s_{i}\right)=p_{e}\left(s_{j}\right)$, then agents consider equity and debt to be perfect substitutes, so that such an equilibrium will coincide with an equilibrium of the stock market economy. The Appendix proves that an equilibrium in which $p_{e}\left(s_{i}\right)=p_{e}\left(s_{j}\right)$ exists only if $\frac{\left(2+\left(\bar{\beta}_{j}\right)^{2}\right)\left(\bar{\beta}_{i}\right)^{2} w_{i 0}-2\left(\bar{\beta}_{j}\right)^{2} w_{j 0}}{\bar{\beta}_{i} \bar{\beta}_{j}\left(w_{i 0}+w_{j 0}\right)}=$ $\frac{\left(1+1, \bar{\beta}_{i}\right) \bar{\beta}, w_{j 1}-\bar{\beta}_{i} w_{i 1}}{\left(w_{i 1}+w_{j 1}\right)}$

The stock-bond economy is designed to conform to the Cox, Ross, and Rubinstein [1979] discrete-time interpretation of the Black-Scholes option pricing formula. 
Under the conditions of Claim 4 there is a unique equilibrium with two states of nature and the price of equity differs across these two states.

We now consider what will occur if in addition agents are allowed to trade a one-period European call option. We term this the "stock-bond-option economy." Claim 5 follows immediately from Cox, Ross, and Rubinstein [1979].

Claim 5 Any Pareto optimal equilibrium allocation of the stock-bond economy is also an equilibrium allocation of the stock-bond-option economy.

Equilibria of the stock-bond economy were such that debt and equity contracts were already sufficient to allow for full movement of income across all fundamental states; therefore, there is an equilibrium in which any option contract will be redundant and neither prices nor the allocation will be changed by its introduction.

Although it would be difficult to construct a discrete-time general equilibrium example in which this logic is better guaranteed to hold, we have the following,

Claim 6 With or without the conditions of Claim 4, sunspot equilibria exist in the stock-bond-option economy.

Proof: See the Appendix

Table 3 provides an example in which the conditions of Claim 4 hold. The top panel presents the unique equilibrium of the stock-bond economy. There are two states in this equilibrium at time $1, s_{i}$ and $s_{j}$, each corresponding to a realization preferences. The bottom panel of Table 3 presents a sunspot equilibrium of the stock-bond-option economy. In this equilibrium there are four states, $s_{i}, \tilde{s}_{i}, s_{j}$ and $\tilde{s}_{j}$, where $i$ desires consumption in states $s_{i}$ and $\tilde{s}_{i}$, and $j$ desires consumption in states $s_{j}$ and $\tilde{s}_{j}$. The probability of each state is $\frac{1}{4}$.

Clearly the sunspot equilibrium is Pareto inferior to the stock-bond equilibrium. As was the case in the first example, the price of the option would substantially differ in the two equilibria. If it were offered in the equilibrium of the top panel 


\begin{tabular}{|c|c|c|c|c|c|c|}
\hline$t, s_{t}$ & $p_{e}\left(s_{t}\right)$ & $p_{b}\left(s_{t}\right)$ & $p_{o}\left(s_{t}\right)$ & $c_{i}\left(s_{t}\right)$ & $c_{j}\left(s_{t}\right)$ & $d_{0}$ \\
\hline \multicolumn{7}{|c|}{ stock-bond, Pareto optimal equilibrium } \\
\hline $0, s_{0}$ & 0.53 & \multirow[t]{3}{*}{0.31} & & 0.71 & 0.76 & \multirow[t]{3}{*}{-0.53} \\
\hline $1, s_{i}$ & 1.8 & & & 2 & 0 & \\
\hline $1, s_{j}$ & 1.6 & & & 0 & 2 & \\
\hline \multicolumn{7}{|c|}{ stock-bond-option equilibrium with sunspots } \\
\hline $0, s_{0}$ & 0.40 & 0.42 & 0.03 & 0.77 & 0.83 & -0.40 \\
\hline $1, s_{i}$ & 1.8 & & & 2 & $\mathbf{0}$ & \\
\hline $1, \tilde{s}_{i}$ & 0.56 & & & 0.62 & 1.38 & \\
\hline $1, s_{j}$ & 1.6 & & & $\mathbf{0}$ & 2 & \\
\hline $1, \tilde{s}_{j}$ & 0.51 & & & 1.37 & 0.63 & \\
\hline
\end{tabular}

Parameters: $\beta_{i}>0$ in states $s_{i}$ and $\tilde{s}_{i} ; \beta_{j}>0$ in states $s_{j}$ and $\tilde{s}_{j} .\left(\bar{\beta}_{i}, w_{i 0}, w_{i 1}\right)=\left(\frac{9}{10}, 1,1\right),\left(\bar{\beta}_{j}, w_{j 0}, w_{j 1}\right)=\left(\frac{8}{10}, 1,1\right)$; $A=1 ; k=\frac{3}{2}$.

Table 3: Two equilibria.

of Table 3 , the option would be redundant and, defining $q \equiv \frac{p_{e}\left(s_{0}\right)-p_{b}\left(s_{0}\right) p_{e}\left(s_{j}\right)}{p_{b}\left(s_{0}\right)\left(p_{e}\left(s_{i}\right)-p_{e}\left(s_{j}\right)\right)}$, its price would be

$$
\begin{aligned}
p_{o}\left(s_{0}\right) & =\left[q\left(p_{e}\left(s_{i}\right)-k\right)+(1-q)\left(p_{e}\left(s_{j}\right)-k\right)\right] p_{b}\left(s_{0}\right) \\
& \approx 0.06
\end{aligned}
$$

\section{Conclusion}

The results of this paper provide robust counterexamples to the two most prevalent views of options markets in finance. While Ross has demonstrated that the adidition of option markets can help complete markets, our examples demonstrate that the addition of option markets can instead increase the number of events which agents need to insure against. While models such as Black-Scholes treat options as reclundant, our second example demonstrates that there may be equilibria in which the addition of an option market is not redundant even when markets are initially complete.

There appears to be nothing particularly special about the model we have pre- 
sented. The examples are robust to small perturbations of the parameters of the model, and while the assumption that agents do not desire consumption in certain states is clearly special, our examples are robust to perturbations of this ass umption as well. More generally, we have also constructed similar numerical exarnples where the uncertainty is with regard to endowments at times 1 and 2 , rather than preferences. While there are conditions under which one can guarantee that the introduction of an option market cannot introduce sunspot equilibria (for instance this would be the case in a representative agent economy), it appears that ;hese conditions are rather strict.

While we have focused exclusively on option markets in the paper, the nature of the examples make clear that the possibility of similar results exist whenever aggents trade any type of nonlinear, price contingent asset. The results may also carry over to other types of contractual relations which mimic an option market, for instance debt contracts are similar to an option contract when the possibility of bankruptcy exists.

The results may indicate the need for a precise definition of what it means for an asset to be "redundant." For example, while agents would view an auded option contract as unnecessary in the stock-bond economy, they may view an aidded bond as quite useful in the stock-option economy, and one would not want to assert that an option market would be redundant in the second example without some further assumption ruling out sunspot equilibria. Accordingly, there is a hierarchy of increasingly stronger definitions of redundancy: an asset may be redundant at some strict subset of the equilibria of the economy which exist before its introduction, at all the equilibria of the economy which exist before its introduction, at all equilibria of the economy which exist before and after its introduction, and/or at all points along excess demand. The examples make it clear that even under the best of circumstances option markets may satisfy only the first or second definitions. 


\section{Appendix}

Claim 3, part (iii) of Claim 4, and Claim 6 are proved by construction.

The proof of Claim 1 establishes that all uncertainty is resolved at time 1. Given $y_{h}\left(s_{0}\right)$, at time 1 agent's demands are given by (7). The equilibrium price of one share of stock must therefore satisfy

$$
p_{e}\left(s_{1}\right)= \begin{cases}\frac{\beta_{i}\left(s_{1}\right)}{1+\beta_{i}\left(s_{1}\right)}\left[w_{i 1}+y_{i}\left(s_{0}\right) \cdot x\left(s_{1}\right)\right] & \text { if } \bar{\beta}_{i}>0 \\ \frac{\beta_{j}\left(s_{1}\right)}{1+\beta_{j}\left(s_{1}\right)}\left[w_{j 1}+y_{j}\left(s_{0}\right) \cdot x\left(s_{1}\right)\right] & \text { if } \bar{\beta}_{j}>0\end{cases}
$$

Since there is no further demand for financial assets at time 2 , in equilibrium $p_{n}\left(s_{2}\right)=0$ for all $n$ and $s_{2} \in S_{2}$, and therefore the equilibrium price of a call option at time 1 must be $p_{o}\left(s_{1}\right)=0$. If the risk-free bond is offered, then arbitrage implies that at time 1 we must have $p_{b}\left(s_{1}\right)=\frac{p_{c}\left(s_{1}\right)}{d_{2}}$.

Define $A_{h}\left(s_{1}\right)=w_{h 1}+y_{h}\left(s_{0}\right) \cdot x\left(s_{1}\right), S_{h}=\left\{s_{1} \in S_{1} \mid \beta_{h}\left(s_{1}\right)>0\right\}$, and $\bar{S}_{h}=$ $S_{1}-S_{h}$. Using (7) we can rewrite the consumer's problem as:

$$
\max \ln \left(c_{h}\left(s_{0}\right)\right)+\sum_{s_{1} \in S_{h}} \pi\left(s_{1}\right)\left(\bar{\beta}_{h}+\bar{\beta}_{h}^{2}\right) \ln \left(A_{h}\left(s_{1}\right)\right)+\sum_{s_{1} \in \bar{S}_{h}} \lambda_{h}\left(s_{1}\right)\left(A_{h}\left(s_{1}\right)\right)
$$

subject to

$$
c_{h}\left(s_{0}\right)=w_{h 0}+y_{h}\left(s_{-1}\right) \cdot x\left(s_{0}\right)-y_{h}\left(s_{0}\right) \cdot p\left(s_{0}\right)
$$

and, for all $s_{1} \in \bar{S}_{h}$ :

$$
\begin{aligned}
\lambda_{h}\left(s_{1}\right) A_{h}\left(s_{1}\right) & =0 \\
\lambda_{h}\left(s_{1}\right) & \geq 0 \\
A_{h}\left(s_{1}\right) & \geq 0 .
\end{aligned}
$$

The first order conditions associated with this problem are, in addition to the constraints (A3) - (A6):

$$
\frac{p_{n}\left(s_{0}\right)}{c_{h}\left(s_{0}\right)}=\sum_{s_{1} \in S_{h}} \pi\left(s_{1}\right)\left(\bar{\beta}_{h}+\bar{\beta}_{h}{ }^{2}\right) \frac{x_{n}\left(s_{1}\right)}{A_{h}\left(s_{1}\right)}+\sum_{s_{1} \in \bar{S}_{h}} \lambda_{h}\left(s_{1}\right) x_{n}\left(s_{1}\right)
$$

fo:: $n=1 \ldots N$. 


\section{Proof of Claim 4, part (iii):}

Claim 1 established that there are no sunspot equilibria of the stock market economy, therefore we assume that there are two states at time $1, s_{i}$ and $s_{j}$, where $\bar{\beta}_{i}>0$ in state $s_{i}$ and $\bar{\beta}_{j}>0$ in state $s_{j}$. If $p_{e}\left(s_{i}\right)=p_{e}\left(s_{j}\right)$ then $\lambda_{i}\left(s_{j}\right)=\lambda_{j}\left(s_{i}\right)=0$ at an equilibrium of the stock market economy. Since we wish to find conditions under which equilibria of the stock market economy with $p_{e}\left(s_{i}\right)=p_{e}\left(s_{j}\right)$ exist, we characterize the set of equilibria in which $\lambda_{i}\left(s_{j}\right)=\lambda_{j}\left(s_{i}\right)=0$.

Agent $h$ 's demands are determined by (7), (A3), and:

$$
c_{h}\left(s_{0}\right)=\frac{p_{e}\left(s_{0}\right)}{p_{e}\left(s_{h}\right)} \frac{2 A_{h}\left(s_{h}\right)}{\bar{\beta}_{h}+\tilde{\beta}_{h}^{2}}
$$

This and (4),(5) yield the unique price vector:

$$
\begin{aligned}
& p_{e}\left(s_{0}\right)=\frac{2\left(w_{i 0}+w_{j 0}\right)}{2+\bar{\beta}_{i}^{2}+\bar{\beta}_{j}^{2}} \\
& p_{e}\left(s_{i}\right)=\frac{\bar{\beta}_{i} w_{i 1}}{1+\bar{\beta}_{i}-\bar{\beta}_{i} \theta} \\
& p_{e}\left(s_{j}\right)=\frac{\bar{\beta}_{j} w_{j 1}}{1+\bar{\beta}_{j} \theta}
\end{aligned}
$$

where $\theta=\frac{\left(2+\bar{\beta}_{j}^{2}\right) \bar{\beta}_{i}^{2} w_{i 0}-2 \bar{\beta}_{j}^{2} w_{j 0}}{\bar{\beta}_{i}^{2} \bar{\beta}_{j}^{2}\left(w_{i 0}+w_{j 0}\right)}$. Constraint (A6) will be satisfied if and only if

$$
-\frac{w_{i 1}}{\bar{\beta}_{j}\left(w_{i 1}+w_{j 1}\right)} \leq \theta \leq 1+\frac{w_{j 1}}{\bar{\beta}_{i}\left(w_{i 1}+w_{j 1}\right)},
$$

which is necessary and sufficient for the above equations to represent an equilibrium. The price equations imply that $p_{e}\left(s_{i}\right)=p_{e}\left(s_{j}\right)$ only if $\theta=\frac{\left(1+\bar{\beta}_{i}\right) \bar{\beta}_{j} w_{j 1}-\bar{\beta}_{i} w_{i 1}}{\bar{\beta}_{i} \bar{\beta}_{j}\left(w_{i 1}+w_{j 1}\right)}$, which proves part (iii) of Claim 4.

\section{Proof of Claim 3:}

We wish to construct a three-state sunspot equilibrium of the stock-option economy. Without loss of generality, assume that $\bar{\beta}_{i}>0$ in states $s_{i}$ and $\tilde{s}_{i}$, and $\bar{\beta}_{j}>0$ in state $s_{j}$. We construct an equilibrium in which $p_{e}\left(s_{i}\right)>k, p_{e}\left(\tilde{s}_{i}\right)<k$, and $p_{e}\left(s_{j}\right)<k$. 
Agent $j$ 's demands must satisfy:

$$
\frac{p_{o}\left(s_{0}\right)}{c_{j}\left(s_{0}\right)}=\left(p_{e}\left(s_{i}\right)-k\right) \lambda_{j}\left(s_{i}\right)
$$

which implies that $\lambda_{j}\left(s_{i}\right)=\left[\frac{p_{0}\left(s_{0}\right)}{p_{\mathrm{e}}\left(s_{i}\right)-k}\right] \frac{1}{c_{j 0}}>0$. Therefore $A_{j}\left(s_{i}\right)=0$. Combining this with the equilibrium condition (4) determines that $A_{i}\left(s_{i}\right)=\left(1+\bar{\beta}_{i}\right)\left(w_{i 1}+w_{j 1}\right)$ ard $p_{e}\left(s_{i}\right)=\bar{\beta}_{i}\left(w_{i 1}+w_{j 1}\right)$. If $\lambda_{j}\left(\tilde{s}_{i}\right)$ is also strictly positive then the same logic implies that $p_{e}\left(\tilde{s}_{i}\right)=p_{e}\left(s_{i}\right)$. We therefore construct an equilibrium in which $\lambda_{j}\left(\tilde{s}_{i}\right)=$ $\lambda_{i}\left(s_{j}\right)=0$. Construction of an equilibrium in which $\lambda_{i}\left(s_{j}\right)>0$ follows along similar lines.

Assuming that $\lambda_{j}\left(\tilde{s}_{i}\right)=\lambda_{i}\left(s_{j}\right)=0$, agent $i$ 's demands are determined by (7), (A.3), and:

$$
\begin{aligned}
c_{i}\left(s_{0}\right) & =\left[\frac{p_{o}\left(s_{0}\right)}{p_{e}\left(s_{i}\right)-k}\right] \frac{A_{i}\left(s_{i}\right)}{\pi\left(s_{i}\right)\left(\bar{\beta}_{i}+\bar{\beta}_{i}^{2}\right)} \\
c_{i}\left(s_{0}\right) & =\left[\frac{p_{e}\left(s_{0}\right)}{p_{e}\left(\tilde{s}_{i}\right)}-\frac{p_{e}\left(s_{i}\right)}{p_{e}\left(\tilde{s}_{i}\right)} \frac{p_{o}\left(s_{0}\right)}{p_{e}\left(s_{i}\right)-k}\right] \frac{A_{i}\left(\tilde{s}_{i}\right)}{\pi\left(\tilde{s}_{i}\right)\left(\bar{\beta}_{i}+\bar{\beta}_{i}^{2}\right)} .
\end{aligned}
$$

Agent $j$ 's demands are determined by (7), (A3), and:

$$
\begin{aligned}
& A_{j}\left(s_{i}\right)=0 \\
& c_{j}\left(s_{0}\right)=\left[\frac{p_{e}\left(s_{0}\right)}{p_{e}\left(s_{j}\right)}-\frac{p_{e}\left(s_{i}\right)}{p_{e}\left(s_{j}\right)} \frac{p_{o}\left(s_{0}\right)}{p_{e}\left(s_{i}\right)-k}\right] \frac{A_{j}\left(s_{j}\right)}{\pi\left(s_{j}\right)\left(\bar{\beta}_{j}+\bar{\beta}_{j}^{2}\right)} .
\end{aligned}
$$

These equations and (4),(5) yield the unique price vector:

$$
\begin{aligned}
& p_{e}\left(s_{0}\right)=\frac{w_{i 0}+w_{j 0}}{1+\frac{2}{\bar{\beta}_{i}^{2}}+\frac{4 \pi\left(\bar{s}_{i}\right)}{\bar{\beta}_{j}^{2}}} \\
& p_{o}\left(s_{0}\right)=\frac{2 \pi\left(s_{i}\right)\left(p_{e}\left(s_{i}\right)-k\right)}{p_{e}\left(s_{i}\right)} p_{e}\left(s_{0}\right) \\
& p_{e}\left(s_{i}\right)=\bar{\beta}_{i}\left(w_{i 1}+w_{j 1}\right) \\
& p_{e}\left(\tilde{s}_{i}\right)=\frac{\bar{\beta}_{i} w_{i 1}}{1+\bar{\beta}_{i} \theta} \\
& p_{e}\left(s_{j}\right)=\frac{\bar{\beta}_{j} w_{j 1}}{1+\bar{\beta}_{j}-\bar{\beta}_{j} \theta}
\end{aligned}
$$

where $\theta=\frac{w_{j 0}}{2 \pi\left(\tilde{s}_{i}\right) p_{e}\left(s_{0}\right)}+\frac{\pi\left(s_{i}\right)}{\pi\left(\bar{s}_{i}\right)} \frac{w_{11}}{p_{e}\left(s_{1}\right)}-\frac{2}{\bar{\beta}_{j}^{2}}$. 
To determine that this is an equilibrium we must verify that (A6) is satisfied and that $p_{e}\left(s_{i}\right)>k, p_{e}\left(\tilde{s}_{i}\right)<k$, and $p_{e}\left(s_{j}\right)<k$. (A6) will be satisfied if and only if:

$$
-\frac{w_{j 1}}{\bar{\beta}_{i}\left(w_{i 1}+w_{j 1}\right)} \leq \theta \leq 1+\frac{w_{i 1}}{\bar{\beta}_{j}\left(w_{i 1}+w_{j 1}\right)}
$$

If

$$
\frac{4 \pi\left(\tilde{s}_{i}\right)}{\bar{\beta}_{j}^{2}}<\frac{w_{j 0}}{p_{e}\left(s_{0}\right)}+\frac{w_{j 1}}{\bar{\beta}_{i}\left(w_{i 1}+w_{j 1}\right)}<\frac{2 \pi\left(\tilde{s}_{i}\right)\left(2+\bar{\beta}_{j}+\bar{\beta}_{j}^{2}\right)}{\bar{\beta}_{j}^{2}},
$$

then $p_{e}\left(s_{i}\right)>\min \left[p_{e}\left(\tilde{s}_{i}\right), p_{e}\left(s_{j}\right)\right]$ and one can choose a $k$ satisfying $p_{e}\left(s_{i}\right)>k$, $p_{e}\left(\tilde{s}_{i}\right)<k$, and $p_{e}\left(s_{j}\right)<k$.

Table 2 of the text demonstrates that parameters which (strictly) meet these inequality constraints exist.

\section{Proof of Claim 6:}

We wish to construct a four-state sunspot equilibrium of the stock-bond-option economy. Assume that $\bar{\beta}_{i}>0$ in states $s_{i}$ and $\tilde{s}_{i}$, and $\bar{\beta}_{j}>0$ in states $s_{j}$ and $\tilde{s}_{j}$. We construct an equilibrium in which $p_{e}\left(s_{i}\right)>k, p_{e}\left(\tilde{s}_{i}\right)<k, p_{e}\left(s_{j}\right)>k$, and $p_{e}\left(\tilde{s}_{j}\right)<k$. The logic of the proof of Claim 3 also indicates that we must have $\lambda_{i}\left(s_{j}\right) \lambda_{i}\left(\tilde{s}_{j}\right)=0$ and $\lambda_{j}\left(s_{i}\right) \lambda_{j}\left(\tilde{s}_{i}\right)=0$ at any sunspot equilibrium. We have arbitrarily chosen to construct an equilibrium in which $\lambda_{i}\left(\tilde{s}_{j}\right)=\lambda_{j}\left(\tilde{s}_{i}\right)=0$ and $\lambda_{i}\left(s_{j}\right)$ and $\lambda_{j}\left(s_{i}\right)$ are positive.

Define $\gamma_{h} \equiv \frac{2}{2+\bar{\beta}_{h}+\bar{\beta}_{h}^{2}}$. Assuming that $\lambda_{i}\left(\tilde{s}_{j}\right)=\lambda_{j}\left(\tilde{s}_{i}\right)=0$ and $\lambda_{i}\left(s_{j}\right)$ and $\lambda_{i}\left(s_{i}\right)$ are positive, agent $i$ 's demands are determined by (7), (A3), and:

$$
\begin{aligned}
A_{i}\left(s_{j}\right) & =0 \\
c_{i}\left(s_{0}\right) & =\gamma_{i}\left[w_{i 0}+p_{b}\left(s_{0}\right) w_{i 1}\right] \\
c_{i}\left(s_{0}\right) & =\left[\frac{p_{e}\left(s_{0}\right)\left(p_{e}\left(s_{j}\right)-k\right)-p_{e}\left(s_{j}\right) p_{o}\left(s_{0}\right)}{\frac{\bar{\beta}_{i}^{2}}{2}\left(p_{e}\left(s_{j}\right)-k\right) A_{i}\left(s_{i}\right)-\pi\left(s_{i}\right) \frac{\bar{\beta}_{i}+\bar{\beta}_{i}^{2}}{2}\left(p_{e}\left(s_{i}\right)-k\right) p_{e}\left(s_{j}\right)}\right] A_{i}\left(s_{i}\right) .
\end{aligned}
$$

Agent $j$ 's demands are determined by (7), (A3), and:

$$
A_{j}\left(s_{i}\right)=0
$$




$$
\begin{aligned}
& c_{j}\left(s_{0}\right)=\gamma_{j}\left[w_{j 0}+p_{b}\left(s_{0}\right) w_{j 1}\right] \\
& c_{j}\left(s_{0}\right)=\left[\frac{p_{e}\left(s_{0}\right)\left(p_{e}\left(s_{i}\right)-k\right)-p_{e}\left(s_{i}\right) p_{o}\left(s_{0}\right)}{\overline{\bar{\beta}}_{j}^{2}\left(p_{e}\left(s_{i}\right)-k\right) A_{j}\left(s_{j}\right)-\pi\left(s_{j}\right) \frac{\bar{\beta}_{j}+\bar{\beta}_{j}^{2}}{2}\left(p_{e}\left(s_{j}\right)-k\right) p_{e}\left(s_{i}\right)}\right] A_{j}\left(s_{j}\right) .
\end{aligned}
$$

These equations and (4),(5) yield the unique price vector:

$$
\begin{aligned}
& p_{e}\left(s_{0}\right)=\frac{\left(w_{i 0}+w_{j 0}\right)\left(\alpha_{j} \bar{\beta}_{i} \gamma_{i} w_{i 1}-\alpha_{i} \bar{\beta}_{j} \gamma_{j} w_{j 1}\right)+\gamma_{i} \gamma_{j}\left(\alpha_{j} \bar{\beta}_{i}+\alpha_{i} \bar{\beta}_{j}\right)\left(w_{i 0} w_{j 1}-w_{j 0} w_{i 1}\right)}{\alpha_{j} \bar{\beta}_{i} \gamma_{i} w_{i 1}-\alpha_{i} \bar{\beta}_{j} \gamma_{j} w_{j 1}-\alpha_{i} \alpha_{j} k\left(\bar{\beta}_{i}-\bar{\beta}_{j}\right)\left(\gamma_{i} w_{i 1}+\gamma_{j} w_{j 1}\right)} \\
& p_{b}\left(s_{0}\right)=\frac{\left(1-\gamma_{i}\right) w_{i 0}+\left(1-\gamma_{j}\right) w_{j 0}-p_{e}\left(s_{0}\right)}{\gamma_{i} w_{i 0}+\gamma_{j} w_{j 0}} \\
& p_{o}\left(s_{0}\right)=\frac{\alpha_{i}\left(p_{e}\left(s_{j}\right)-k\right) p_{e}\left(s_{0}\right)-\gamma_{i}\left(w_{i 0}+p_{b}\left(s_{0}\right) w_{i 1}\right)}{\alpha_{i} p_{e}\left(s_{j}\right)} \\
& p_{e}\left(s_{i}\right)=\frac{\bar{\beta}_{i}\left(w_{i 1}+w_{j 1}\right)}{p_{e}\left(\tilde{s}_{i}\right)}=\frac{\frac{\bar{\beta}_{i}\left(1+\bar{\beta}_{i}\right)}{\bar{\beta}_{i}-\bar{\beta}_{j}}\left(\bar{\beta}_{j}\left(w_{i 1}+w_{j 1}\right)-k\right)+\theta k}{\theta \bar{\beta}_{i}-\bar{\beta}_{i}-1} \\
& p_{e}\left(s_{j}\right)=\frac{\bar{\beta}_{j}\left(w_{i 1}+w_{j 1}\right)}{1+\theta \bar{\beta}_{j}} \\
& p_{e}\left(\tilde{s}_{j}\right)=\frac{\bar{\beta}_{j}\left(1+\bar{\beta}_{j}\right)}{\bar{\beta}_{i}-\bar{\beta}_{j}}\left(\bar{\beta}_{i}\left(w_{i 1}+w_{j 1}\right)-k\right)+\theta k-k
\end{aligned}
$$

where

and

$$
\begin{gathered}
\theta=\frac{\frac{1+\bar{\beta}_{i}}{\bar{\beta}_{i}-\bar{\beta}_{j}}\left[p_{o}\left(s_{0}\right)-\left(p_{e}\left(s_{j}\right)-k\right) p_{b}\left(s_{0}\right)\right]-\frac{\gamma_{i}\left(\bar{\beta}_{i}+\bar{\beta}_{i}^{2}\right)}{2}\left[w_{i 0}+p_{b}\left(s_{0}\right) w_{i 1}\right]}{p_{b}\left(s_{0}\right) k+p_{o}\left(s_{0}\right)-p_{e}\left(s_{0}\right)}, \\
\alpha_{i}=\frac{2}{\bar{\beta}_{i}^{2}\left[\bar{\beta}_{j}\left(w_{i 1}+w_{j 1}\right)-k\right]-2 \pi\left(s_{i}\right) \bar{\beta}_{i} \bar{\beta}_{j}\left[\bar{\beta}_{i}\left(w_{i 1}+w_{j 1}\right)-k\right]},
\end{gathered}
$$

$$
\alpha_{j}=\frac{2}{\bar{\beta}_{j}^{2}\left[\bar{\beta}_{i}\left(w_{i 1}+w_{j 1}\right)-k\right]-2 \pi\left(s_{j}\right) \bar{\beta}_{i} \bar{\beta}_{j}\left[\bar{\beta}_{j}\left(w_{i 1}+w_{j 1}\right)-k\right]} .
$$

Since we wish to satisfy the condition $\bar{\beta}_{i} \neq \bar{\beta}_{j}$, we will assume that $\bar{\beta}_{i}>\bar{\beta}_{j}$. The assumption that $p_{e}\left(s_{i}\right)>k$ and $p_{e}\left(s_{j}\right)>k$ will be satisfied if $\bar{\beta}_{j}\left(w_{i 1}+w_{j 1}\right)>k$. Prices will be strictly positive, (A6) will hold, and the assumptions that $p_{e}\left(\tilde{s}_{i}\right)<k$ and $p_{e}\left(\tilde{s}_{j}\right)<k$ will be satisfied if $k>0$ and $\theta<\frac{1+\bar{\beta}_{i}}{\bar{\beta}_{i}-\bar{\beta}_{j}}-\frac{1+\bar{\beta}_{j}}{\bar{\beta}_{i}-\bar{\beta}_{j}} \frac{p_{e}\left(s_{i}\right)}{k}$. By construction $\lambda_{i}\left(\tilde{s}_{j}\right)=\lambda_{j}\left(\tilde{s}_{i}\right)=0$. The assumption that $\lambda_{i}\left(s_{j}\right)$ and $\lambda_{j}\left(s_{i}\right)$ are positive will be satisfied if $c_{h}\left(s_{0}\right)<\frac{2 p_{e}\left(s_{0}\right)}{\bar{\beta}_{h}^{2}}$ for $h=i, j$. A solution which meets these inequalities constitutes an equilibrium.

Table 3 of the text demonstrates that parameters which meet these constraints ancl satisfy the conditions of Claim 4 exist. 


\section{References}

Arrow, K.J., "Le rôle des valeurs boursières pour la répartition la meilleure des risques," Econométrie, Colloque Internationaux du Centre National cle la Recherche Scientifique, 11, 1953, p. 41-47. [English translation: “The Role of Securities in the Optimal Allocation of Risk Bearing," Review of Economic Studies, 31, 1964, p. 91-96.]

Balasko, Y. and D. Cass, "The Structure of Financial Equilibrium with Exogenous Yields: The Case of Incomplete Markets," Econometrica, 57, 1989, p. 135-163.

Black, F. and M. Scholes, "The Pricing of Options and Corporate Liabilities," Journal of Political Economy, 81, 1973, p.637-659.

Brown, D.J. and S.A. Ross, "Spanning, Valuation and Options," Economic Theory, 1,1991 , p. 3-12.

Cass, D., "Sunspots and Incomplete Financial Markets: The Leading Example," in The Economics of Imperfect Competition and Employment: Joan Robinson and Beyond, G. Feiwel ed., MacMillan, London, 1989.

, "Sunspots and Incomplete Financial Markets: the General Case," Economic Theory, 2, 1992, p. 341-358.

Cass, D. and K. Shell, "Do Sunspots Matter?" Journal of Political Economy, 91, 1983, p. 193-227.

Cox, J.C., Ross, S.A., and M. Rubinstein, "Option Pricing: A Simplified Approach," Journal of Financial Economics, 7, 1979, p. 229-263.

Detemple, J. and L. Selden, "A General Equilibrium Analysis of Option and Stock Market Interactions," International Economic Review, 32, 1991, p. 279-303.

Ekern, S. and R.B. Wilson, "On the Theory of the Firm in an Economy with Incomplete Markets," The Bell Journal of Economics and Management Science, 5,1974 , p. $171-180$. 
Friesen, P. "The Arrow-Debreu Model Extended to Financial Assets," Econometrica, 47, 1979, p. 689-727.

Cieanakoplos, J. and A. Mas-Collel, "Real Indeterminacy with Financial Assets," Journal of Economic Theory, 47, 1989, p. 22-39.

Gennotte, G. and H. Leland, "Market Liquidity, Hedging, and Crashes," American Economic Review, 61, 1990, p. 999-1021.

Gireen, R.C. and R.A. Jarrow, "Spanning and Completeness in Markets with Contingent Claims," Journal of Economic Theory, 41, 1987, p. 202-210.

Hens, T., "Do Sunspots Matter when Spot Market Equilibria are Unique?" mimeo, University of Bonn, 1994.

Kajii, A. "On the Role of Options in Sunspot Equilibria," CARESS working paper no.91-24, 1991.

Krasa, S., "Existence of Competitive Equilibria for Options Markets," Journal of Economic Theory, 47, 1989, p. 413-421.

Krasa, S. and J. Werner, "Equilibria with Options: Existence and Optimality," Journal of Economic Theory, 54, 1991, p. 305-320.

M.cManus, D., "Options: Equilibrium and Optimality Properties," mimeo, 1986.

Mas-Collel, A., "Three Observations on Sunspots and Asset Redundancy," in Economic Analysis of Markets and Games: Essays in Honor of Frank Hahn, P. Dasgupta et al. eds., MIT Press, Cambridge, MA, 1992, p. 465-474.

Polemarchakis, H.M. and B. Ku, "Options and Equilibrium," Journal of Mathematical Economics, 19, 1990, p. 107-112.

Radner, R., "Existence of Equilibrium Plans, Prices and Price Expectations in a Sequence of Markets," Econometrica, 40, 1972, p. 289-303. 
, "A Note on Unanimity of Stockholder's Preferences Among Alternative Production Plans: A Reformulation of the Ekern-Wilson Model," The Bell Journal of Economics and Management Science, 5, 1974, p. 181-184.

Ross, S.A., "Options and Efficiency," Quarterly Journal of Economics, 90, 1976, p. $75-89$.

Shell, K. "Monnaie et allocation intertemporelle," CNRS Séminaire d'Econométrie de M. Edmond Malinvaud, Paris, 1977. 


\section{International Finance Discussion Papers}

IFDP

Number

Titles

Author(s)

1995

510 Options, Sunspots, and the Creation of Uncertainty

509 Hysteresis in a Simple Model of Currency Substitution

David Bowman

Jon Faust

508 Import Prices and the Competing Goods Effect

Martin Uribe

507 Supply-side Economics in a Global Economy

Phillip Swagel

Enrique G. Mendoza

Linda L. Tesar

506 The Lucas Critique In Practice: Theory Without Measurement

Neil R. Ericsson

John S. Irons

505 Real Exchange Rate Targeting and Macroeconomic Instability

Martin Uribe

$504 \quad$ Inferences from Parametric and Non-Parametric Covariance Matrix Estimation Procedures

Wouter J. Den Haan

Andrew T. Levin

Martin Uribe

503 Exchange-Rate Based Inflation Stabilization: The Initial Real Effects of Credible Plans

John Ammer

Strategic Returns to International

Diversification: An Application to the Equity

Markets of Europe, Japan, and North America

Jianping Mei

501 Real Exchange Rate Movements in High Inflation Countries

John H. Rogers

Ping Wang

500 Political Competition, Casual Relations Between

Taxes and Spending, and Their Influence on

Government Size: Evidence From State-Level Data

Diane Lim Rogers

John H. Rogers

499 International Stock Price Spillovers and Market

Liberalization: Evidence From Korea, Japan, and the United States

Sang W. Kim

John H. Rogers

$498 \quad$ How Wide is the Border?

Charles Engle

John H. Rogers

497 Constrained Suboptimality in Economies with Limited Communication

David Bowman

Please acldress requests for copies to International Finance Discussion Papers, Division of International Finance, Stop 24, Board of Governors of the Federal Reserve System,

Washington, D.C. 20551 . 


\section{International Finance Discussion Papers}

IFDP

Number

Titles

Author(s)

1995

496 Saving-Investment Associations and Capital Mobility On the Evidence from Japanese Regional Data

Robert Dekle

495 Convertibility Risk, Default Risk, and the Mexdollar Anomaly

494 Government Budget Deficits and Trade Deficits Are Present-Value Constraints Satisfied in Long-Term Data?

Shaghil Ahmed

John H. Roggers

493 Real Shocks and Real Exchange Rates in Really Long-Term Data

John H. Roggers

1994

492 Loss Aversion in a Consumption/Savings Model

David Bowman

Deborah Minehart

Matthew Riabin

491 Terms-of-Trade Uncertainty and Economic Growth:

Are Risk Indicators Significant in Growth Regressions

Enrique G. Mendoza

490 Politics, Economics, and Investment: Explaining Plant and Equipment Spending by U.S. Direct Investors in Argentina, Brazil, and Mexico

489 On The Dynamic Properties of Asymmetric Models of Real GNP

Allan D. Bıunner

488 A distributed block approach to solving near-block-diagonal systems with an application to a large macroeconometric model

Guy V.G. Stevens

Jon Faust

Ralph Tryon

487 Conditional and Structural Error Correction Models

Neil R. Ericssson

486 Bank Positions and Forecasts of Exchange Rate Movements

485 Technological Progress and Endogenous Capital Depreciation: Evidence from the U.S. and Japan

Michael P. Leahy

Robert Dekle

$484 \quad$ Are Banks Market Timers or Market Makers? Explaining Foreign Exchange Trading Profits

John Ammer

Allan D. Brunner

483 Constant Returns and Small and Markups in U.S. Manufacturing

John G. Fernald

Suanto Basu 